\title{
Experimental observation of signature changes in bulk soil electrical conductivity in response to engineered surface $\mathrm{CO} 2$ leakage
}

\author{
Authors: Xiaobing Zhou,Venkata R. Lakkaraju, \\ Martha Apple, Laura M. Dobeck, Kadie Gullickson, \\ Joseph A. Shaw, Alfred B. Cunningham, Lucian \\ Wielopolski, \& Lee H. Spangler
}

NOTICE: this is the author's version of a work that was accepted for publication in International Journal of Greenhouse Gas Control. Changes resulting from the publishing process, such as peer review, editing, corrections, structural formatting, and other quality control mechanisms may not be reflected in this document. Changes may have been made to this work since it was submitted for publication. A definitive version was subsequently published in International Journal of Greenhouse Gas Control, 7, March 2012. DOI\#10.1016/j.ijggc.2011.12.006.

Zhou X, Lakkaraju VR, Apple M, Dobeck LM, Gullickson K, Shaw JA, Cunningham AB, Wielopolski L, Spangler LH, "Experimental observation of signature changes in bulk soil electrical conductivity in response to engineered surface CO2 leakage," International Journal of Greenhouse Gas Control, March 2012 7:20-29 


\title{
Experimental observation of signature changes in bulk soil electrical conductivity in response to engineered surface $\mathrm{CO}_{2}$
}

leakage

\author{
Xiaobing Zhou ${ }^{\mathrm{a}, *}$, Venkata R. Lakkaraju ${ }^{\mathrm{a}}$, Martha Apple ${ }^{\mathrm{b}}$, Laura M. Dobeck ${ }^{\mathrm{c}}$, \\ Kadie Gullickson ${ }^{\text {c }}$, Joseph A. Shaw d, Alfred B. Cunningham ${ }^{\mathrm{e}}$, Lucian Wielopolski \\ $\mathrm{f}$, Lee H. Spangler ${ }^{\mathrm{c}}$ \\ a Department of Geophysical Engineering, Montana Tech of The University of Montana, 1300 West Park Street, Butte, MT 9701, \\ United States \\ b Department of Biological Sciences, Montana Tech of The University of Montana, Butte, MT 59701, United States \\ ${ }^{c}$ Department of Chemistry and Biochemistry, Montana State University, Bozeman, MT 59717, United States \\ d Department of Electrical and Computer Engineering, Montana State University, Bozeman, MT 59717, United States \\ e Department of Civil Engineering, Montana State University, Bozeman, MT 59717, United States \\ f Environmental Sciences Department, Brookhaven National Laboratory, Upton, NY 11973, United States
}

\begin{abstract}
Experimental observations of signature changes of bulk soil electrical conductivity (EC) due to $\mathrm{CO}_{2}$ leak-age were carried out at a field site at Bozeman, Montana, to investigate the change of soil geophysical properties in response to possible leakage of geologically sequestered $\mathrm{CO}_{2}$. The dynamic evolution of bulk soil EC was measured during an engineered surface leakage of $\mathrm{CO}_{2}$ through in situ continuous monitoring of bulk soil EC, soil moisture, soil temperature, rainfall rate, and soil $\mathrm{CO}_{2}$ concentration to investigate the response of soil bulk EC signature to $\mathrm{CO}_{2}$ leakage. Observations show that: (1) high soil $\mathrm{CO}_{2}$ concentration due to $\mathrm{CO}_{2}$ leakage enhances the dependence of bulk soil EC on soil moisture. The bulk soil EC is a linear multivariate function of soil moisture and soil temperature, the coefficient for soil moisture increased from $2.111 \mathrm{dS}$ for the non-leaking phase to $4.589 \mathrm{dS}$ for the $\mathrm{CO}_{2}$ leaking phase; and the coefficient for temperature increased from $0.003 \mathrm{dS} /{ }^{\circ} \mathrm{C}$ for the non-leaking phase to $0.008 \mathrm{dS} /{ }^{\circ} \mathrm{C}$ for the $\mathrm{CO} 2$ leaking phase. The dependence of bulk soil $\mathrm{EC}$ on soil temperature is generally weak, but leaked $\mathrm{CO}_{2}$ enhances the dependence, (2) after the $\mathrm{CO}_{2}$ release, the relationship between soil bulk EC and soil $\mathrm{CO}_{2}$ concentra-tion observes three distinct $\mathrm{CO}_{2}$ decay modes. Rainfall events result in sudden changes of soil moisture and are believed to be the driving forcing for these decay modes, and (3) within each mode, increasing soil $\mathrm{CO}_{2}$ concentration results in higher bulk soil EC. Comparing the first 2 decay modes, it is found that the dependence of soil EC on soil $\mathrm{CO}_{2}$ concentration is weaker for the first decay mode than the second decay mode.
\end{abstract}

To stabilize the atmospheric $\mathrm{CO}_{2}$ level, geological $\mathrm{CO}_{2}$ sequestration (GCS) for long-term storage in geological formations (such as depleted oil and gas reservoirs, deep brine permeable formations, coal seams, etc.) has been proposed as an important potential remedy (Holloway, 2001; IPCC, 2005). However, there are inevitably unfavorable structural discontinuities and weak points, such as fractures, faults, wells drilled for oil and gas exploration and production, gas permeable channels/faults in the caprocks (Annunziatellis et al., 2008), or geomechanical disruptions due to increased pressure in the reservoir, etc. (Gasda et al., 2004; IPCC, 2005; Pruess, 2005; Celia et al., 2009; Grimstad et al., 2009). If the capillary entry pressure of the fractures and faults or aban-doned wells is exceeded by over-pressurization or the buoyancy of accumulated $\mathrm{CO}_{2}$, the sequestered $\mathrm{CO}_{2}$ can migrate out from the traps and, eventually, enter into the atmosphere (Oldenburg and Unger, 2003; Chang and Bryant, 2009; Alexander and Bryant, 2009; Bouc et al., 2009). The extent of $\mathrm{CO}_{2}$ leakage related to the storage integrity is one of the key questions associated with the safety of $\mathrm{CO}_{2}$ storage (Hepple and Benson, 2005). Xu et al.'s (2003) simula-tion showed that the $\mathrm{CO}_{2}$ mineral trapping capability after 10,000 years is comparable to $\mathrm{CO}_{2}$ dissolution in pore waters. This means that for injected $\mathrm{CO}_{2}$ to be contained for more than 10,000 years so that mineral trapping becomes significant, the annual leaking rate should not exceed $0.01 \%$. During this period, the $\mathrm{CO}_{2}$ will dissolve into the resident brine, causing it to sink to the bottom of the forma-tion due to its slightly higher density with dissolved $\mathrm{CO}_{2}$ than the background brine and causing secondary $\mathrm{CO}_{2}$ dissolution seques-tration (Bachu and Adams, 2003; Gasda et al., 2004). The dissolved 
$\mathrm{CO}_{2}$ may then react with the rock material to form stable carbonate minerals such as calcite $\left(\mathrm{CaCO}_{3}\right)$, dolomite $\left(\mathrm{CaMg}\left(\mathrm{CO}_{3}\right)_{2}\right)$, siderite $\left(\mathrm{FeCO}_{3}\right)$, and dawsonite $\left(\mathrm{NaAlCO}_{3}(\mathrm{OH})_{2}\right)$, resulting in secondary $\mathrm{CO}_{2}$ mineral sequestration (Haywood et al., 2001; Xu et al., 2003; McCafferty et al., 2009).

To ensure sufficient time for these long-term secondary sequestration processes to occur and to provide safe isolation of the $\mathrm{CO}_{2}$, the development and verification of shallow subsurface monitoring technologies to detect any leaking $\mathrm{CO}_{2}$ or any preferential leaking paths that it may follow is a critical step for the stakeholders and the public at large to be convinced that all potential risks and means of remediation have been studied. These monitoring methods are used to assess the status of $\mathrm{CO}_{2}$ storage in the subsurface geological formations, to assess the possible environmental impact of sequestered $\mathrm{CO}_{2}$ leakage, and to take appropriate remediation actions (Cunningham et al., 2009).

Leaked $\mathrm{CO}_{2}$, if present, will eventually enter the atmosphere through the soil, leading to locally high soil $\mathrm{CO}_{2}$ concentrations. The environmental impact of $\mathrm{CO}_{2}$ on soil is multi-fold. Studies on natural analogs, where naturally produced $\mathrm{CO}_{2}$ is leaking at surface from deep geological units, show that high $\mathrm{CO}_{2}$ concentrations in the soil can affect not only the dissolution kinetics of soil and soil structure (Stephens and Hering, 2004), chemistry and mineralogy (Beaubien et al., 2008), but also soil microbial and plant ecosystems (Macek et al., 2005; Pfanz et al., 2007; Beaubien et al., 2008; Lakkaraju et al., 2010). Impacts on soil microbial ecosystems can include altering community structure, abundance and diversity of microorganisms (Beaubien et al., 2008; Krüger et al., 2009), microbe growth, and microbial processes such as nitrification and denitrification, nitrogen transformations, and organic matter decomposition (Laura, 1974; Frankenberger and Bingham, 1982; Killham and Firestone, 1984; Avrahami et al., 2002; Irshad et al., 2005). Impacts on plant ecosystems can include reduction of respiration and photosynthetic activities (Macek et al., 2005; Pfanz et al., 2007), retardation of plant growth or even death of plants (Lakkaraju et al., 2010), and shifts in the abundance and diversity of plants (Levitt, 1980; Krüger et al., 2009).

All the processes described above, biotic or abiotic, will manifest themselves to some extent in changes to the signature of various soil geophysical properties, such as soil electric conductivity (EC). For instance, the electrical conductivity of a layer, explored up to a depth of about 10 meters with geophysical potential methods such as electrical resistivity, electromagnetics, and self-potential, indicates that an anomalously high conductivity is associated with active, thermo-metamorphically produced $\mathrm{CO}_{2}$ gas vents within the Latera Caldera (central Italy) (Pettinelli et al., 2008; Arts et al., 2009). However, any of the following factors could play a direct or indirect role in altering the electrical conductivity: the gas efflux and soil moisture (Pettinelli et al., 2008), the secondary effect of dissolution (Wang and Jaffe, 2004) and acid-rock interaction that leads to weathering of volcanic soil (Stephens and Hering, 2002). Therefore, the cause of the observed EC anomaly is uncertain for such paleo-thermal mofettes (volcanic gas exhalations). Soil EC is a function of soil properties such as the solid constituents (shape and size of solid particles and distribution, mineralogy), arrangement of voids (porosity, pore size distribution, tortuosity, and connectivity), degree of water saturation (soil moisture), electrical conductivity of the fluid (solute concentration) and temperature (Jackson et al., 1978; Fukue et al., 1999; Samouëlian et al., 2005). The EC of the water solution in soil is a function of the ionic concentration, and that of the solid soil particles is related to the electrical surface charges density at the surface of the constituents. A change in soil EC can be considered as a proxy for the variability of soil geophysical properties and chemical compositions (Banton et al., 1997). We hypothesize that during the leaking process, $\mathrm{CO}_{2}$ will interact with the soil matrix and soil moisture and alter soil

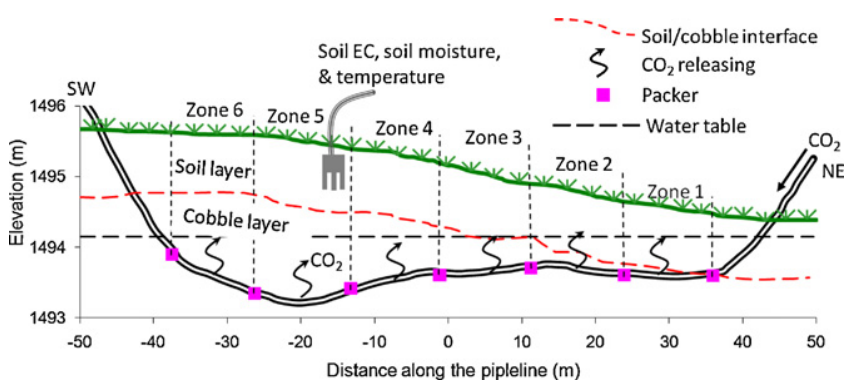

Fig. 1. A sketch of a cross section that runs through the pipeline along which the $\mathrm{CO}_{2}$ was injected and released from 6 zones separated by 7 packers.

geophysical properties such as the bulk soil EC, leaving signatures of leakage within soil that can be detectable. The objective of this research was to study the response of bulk soil EC signatures to $\mathrm{CO}_{2}$ leakage, and to examine the possibility of monitoring $\mathrm{CO}_{2}$ leakage using the soil EC method in the shallow vadose zone.

The EC method is a succinct, quick, and inexpensive analytical tool for salinity measurements. Since total salinity and ion composition in the soil are the two most important factors affecting soil EC (Rhoades et al., 1999; Liu et al., 2006), EC can be a good measure of not only the total salinity but also of the ion composition in the soil water. In this study, we will investigate the dynamic evolution of bulk soil EC during an engineered shallow $\mathrm{CO}_{2}$ leakage of $\mathrm{CO}_{2}$ through in situ continuous monitoring of soil EC, soil moisture, soil temperature, rainfall, and soil volume $\mathrm{CO}_{2}$ concentration.

\section{Methods}

The simulated leakage of $\mathrm{CO}_{2}$ was carried out in the summer of 2009 at a field facility engineered by the Zero Emission Research and Technology Center (ZERT), in an agricultural plot in Bozeman, Montana, USA (Spangler et al., 2010; Lewicki et al., 2010). This research site was developed to allow controlled studies of near surface $\mathrm{CO}_{2}$ transport and detection technologies. As is shown in Fig. 1, a $100 \mathrm{~m}$ long N45E-trending horizontal well with a 70-m long central slotted (perforated) section and 15- and 12-m long unslotted sections on its sloping NE and SW ends, respectively, was installed at the site for the controlled release of $\mathrm{CO}_{2}$. The horizontal well casing was installed through horizontal directional drilling, leaving the overlying layers intact. The slotted section, which consisted of six zones (five zones each $12 \mathrm{~m}$ long and one zone $10 \mathrm{~m}$ long) separated by seven $0.4-\mathrm{m}$ long inflatable packers, was buried at a depth of approximate $2.0-2.3 \mathrm{~m}$ (about $0.5 \mathrm{~m}$ below the groundwater table) within a layer of alluvial sandy gravel, overlaid by a clayey silt layer of about $0.20 \mathrm{~m}$ and a layer of topsoil of approximately $0.30 \mathrm{~m}$. The topsoil of the field site consists primarily of fine-grained organic silts and clays. The soil layer is underlain by a cobble layer. The positions of packers, soil-cobble interface, land surface, and the horizontal well in Fig. 1 were estimated from Figs. 1 and 2 of Oldenburg et al. (2010) and Fig. 1a of Lewicki et al. (2010). The position of the sensors for the soil EC, soil moisture, and soil temperature was also shown in Fig. 1. A shallow $\mathrm{CO}_{2}$ release experiment was conducted from 12:11 pm on July 15 th to $12: 00 \mathrm{pm}$ on August 12th, 2009 at a release rate of 0.2 tons per day. This was an experiment of multiple missions (Spangler et al., 2010), with bulk soil EC measurement being only one of them.

Measurements of bulk soil EC, soil moisture, and soil temperature were carried out using a 5TE instrument (Decagon Devices, Inc.) at a "hotspot" site (centered at $45^{\circ} 39^{\prime} 42.40^{\prime \prime} \mathrm{N}$, $111^{\circ} 4^{\prime} 52.24^{\prime \prime} \mathrm{W}$ ) where the soil $\mathrm{CO}_{2}$ was very high, well above the background soil $\mathrm{CO}_{2}$ concentration $(0.63 \%$ on average, see Section 3 ). The $5 T E$ probe was available only since July 18 , three days after the start of $\mathrm{CO}_{2}$ release. The 5TE is a multi-function three-pronged 
probe that consists of a thermistor and three thin metal electrodes that are $1.0 \mathrm{~cm}$ apart. The probe was vertically inserted into the top soil at a depth of $15 \mathrm{~cm}$ into the vadose zone. Thus, the soil measured by the 5TE is mainly fine-grained silts and clays. The bulk soil EC is measured by applying an alternating electric current $(10 \mathrm{kHz})$ to two electrodes up to $23.1 \mathrm{dS} / \mathrm{m}$ (deciSiemen per meter, $1 \mathrm{dS} / \mathrm{m}=0.1 \mathrm{~S} / \mathrm{m}$ ) with a resolution of $0.01 \mathrm{dS} / \mathrm{m}$ for the range from 0 to $7 \mathrm{dS} / \mathrm{m}$, and a resolution of $0.05 \mathrm{dS} / \mathrm{m}$ for the range from 7 to $23.1 \mathrm{dS} / \mathrm{m}$. Salts in soil have to be in an ionized form to conduct electrically; soil water content provides the solution agent for the ions, governs the available paths of conduction, and is a main factor in determining bulk soil EC values. Volumetric soil moisture is measured up to $50 \%$ in total soil volume with a resolution of $0.08 \%$ by supplying a $70 \mathrm{MHz}$ oscillating electromagnetic wave to another pair of electrodes. The analog signal of each of the probes on the 5TE was digitized and stored in a data logger. Measurements were programmed to be taken every $30 \mathrm{~min}$, to avoid possible errors resulting from ground potential gradients and polarization effects.

Soil temperature changes the composition of salts in the soil and modifies soil respiration (Lloyd and Taylor, 1994). Because the solubility of salts and $\mathrm{CO}_{2}$ in soil water depends on soil temperature, it is expected that soil EC also depends on the temperature. For this reason, soil temperature was also measured. Soil temperature (at $15 \mathrm{~cm}$ depth) was measured by a surface-mounted thermistor with a resolution of $0.1^{\circ} \mathrm{C}$. A tipping-bucket rain gauge manufactured by Hydrological Services was also installed to monitor the rainfall at a time interval of $1 \mathrm{~min}$. It has a $20-\mathrm{cm}$ diameter aperture and measures rainfall in $0.25 \mathrm{~mm}$ increments with up to $\pm 2 \%$ uncertainty for precipitation rates from 1 to $500 \mathrm{~mm} / \mathrm{h}$. The rainfall rate data are then integrated into rate per $30 \mathrm{~min}$, complying with other measurements.

$\mathrm{CO}_{2}$ release rate at each zone was controlled and recorded by a mass flow controller at the zone. There was a mass flow controller for each zone. Logging of the flow rates for all the six mass flow controllers started at 12:35 pm on July 13, 2009 and ended at 17:05 on August 13,2009. $\mathrm{CO}_{2}$ release was started at $12: 11 \mathrm{pm}$ on July 15, 2009 and was shut at 12:00pm on August 12, 009. The soil $\mathrm{CO}_{2}$ volume concentration was measured at the same site as soil EC using Vaisala CARBOCAP ${ }^{\circledR}$ GMT221 infra-red (IR) $\mathrm{CO}_{2}$ probes with in-soil adapters. The sensors were calibrated and linearized up to $20 \%$ in volume and were deployed at a depth of approximately $15 \mathrm{~cm}$. Soil $\mathrm{CO}_{2}$ measurement was started a few weeks before the start of $\mathrm{CO}_{2}$ release so that the background soil $\mathrm{CO}_{2}$ concentration could be estimated. $\mathrm{CO}_{2}$ measurement is through a $\mathrm{CO}_{2}$ absorption band at a wavelength of $4.26 \mu \mathrm{m}$. The atmospheric pressure and temperature compensations due to deviation of measurement conditions from the calibration conditions $\left(101.325 \mathrm{kPa}\right.$ and $\left.25^{\circ} \mathrm{C}\right)$ were made for the $\mathrm{CO}_{2}$ measurement that was taken every 5 min. The soil $\mathrm{CO}_{2}$ concentration at the same time as bulk soil EC, soil moisture, and soil temperature was then retrieved.

\section{Data analysis}

The top panel of Fig. 2 shows the total flow rate for all zones (Fig. 1) and the flow rate for Zone $5 \mathrm{in} \mathrm{kg} /$ day recorded by the mass flow controllers at 1 -min interval. The total flow rate shown here is the sum of the flow rates from all the mass flow controllers in the six zones. Since our measurements of bulk soil EC, soil moisture, soil $\mathrm{CO}_{2}$ concentration were carried out in Zone 5 , the flow rate for this zone is our focus. The total release rate during the releasing period of time is supposed to be 0.2 tons/day. However, there was some noise mainly from the mass flow controller for Zone 5. Flow rates recorded by the mass flow controllers for other zones had much less fluctuation (not shown in Fig. 2). Also, the manual gauges that were in line with Zone 5 did not show the fluctuations in the flow rate as recorded by the mass flow controller for Zone 5 . After $\mathrm{CO}_{2}$ release

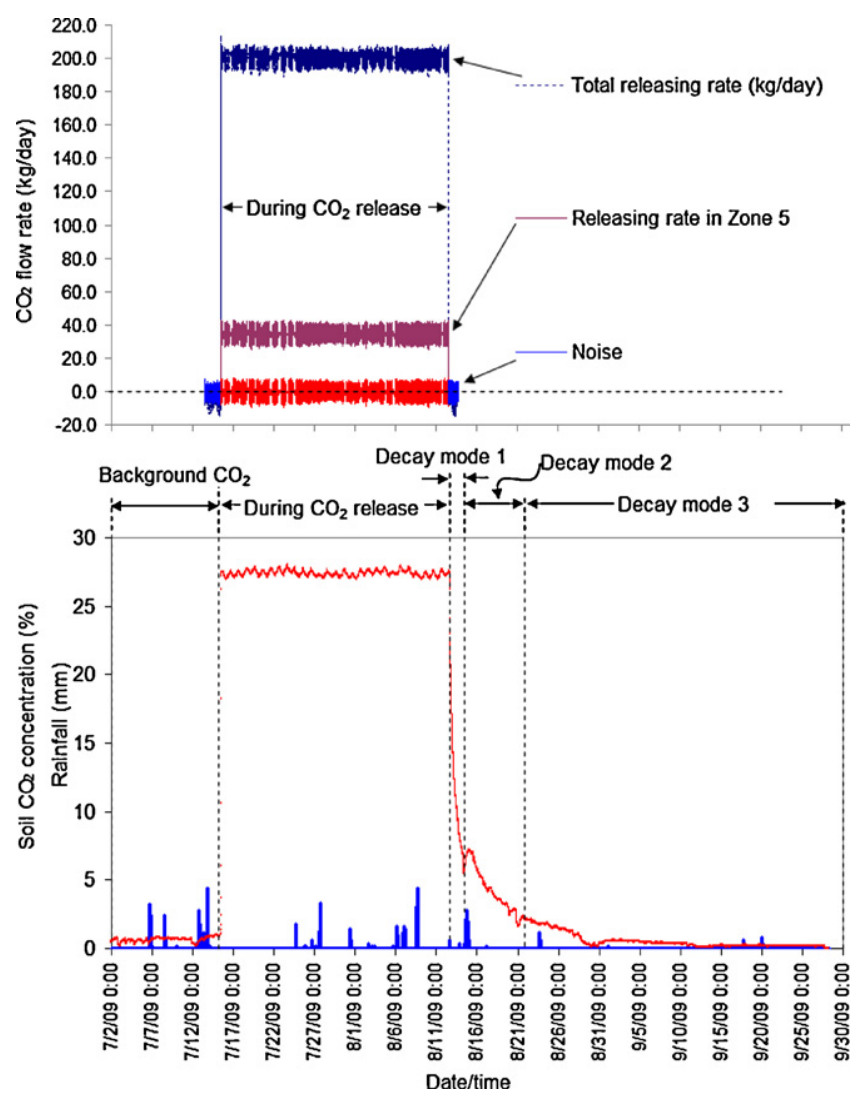

Fig. 2. Top: temporal variation of $\mathrm{CO}_{2}$ releasing rate ( $\mathrm{kg} /$ day) for all 6 zones and Zone 5. Bottom: temporal variation of soil $\mathrm{CO}_{2}$ volume concentration (line) and 30-min integrated rainfall rate (vertical bars). Two parameters share the same vertical axis. The time period from July 2 to September 28, 2009 covers both $\mathrm{CO}_{2}$ pre-release, during-release, and post-release periods. The time periods corresponding to the three post-release $\mathrm{CO}_{2}$ decay modes are also shown.

was terminated at 12:00 pm on August 12, the flow rates recorded by the mass flow controller for Zone 5 from 12:01 pm, August 12 to 17:05, August 13, 2009 are supposed to be noise and were found to have an average (bias) of $-0.26 \mathrm{~kg} / \mathrm{day}$. The average flow rate during release recorded by the mass flow controller for Zone 5 is $34.44 \mathrm{~kg} /$ day. Considering the negative bias of the noise, a releasing rate of $34.70 \mathrm{~kg} /$ day is reasonable. Subtracting $34.70 \mathrm{~kg} /$ day from the flow rates during the release time recorded by the mass flow controller for Zone 5, the supposed noise is shown in the top panel of Fig. 2 (bottom curve), along with the noise levels (in blue) before and after release. Comparison of the noise levels from before, during, and after release, we can see that the peak-peak fluctuations of flow rate during three different periods of time have the same level. Therefore, we can reasonably believe that the fluctuations in the flow rates during release recorded by the mass flow controller for Zone 5 are mainly due to the noise of the controller, not real fluctuations in the flow rates; and the real flow rate is about $34.70 \mathrm{~kg} /$ day during the release.

The bottom panel of Fig. 2 shows the time series (5-min interval) of the soil $\mathrm{CO}_{2}$ volume concentration in the soil air (\%) and rain rate integrated at $30 \mathrm{~min}$ from July 2 to the end of measurement (September 28). The unit for the integrated rain rate is millimeter per half an hour $(\mathrm{mm} / \mathrm{HH})$. As the $\mathrm{CO}_{2}$ sensors were calibrated only up to $20 \%$ in volume, the sensor was saturated during the releasing period of time (July 15-August 12, 2009). The soil $\mathrm{CO}_{2}$ concentration increased rapidly and reached the saturation level of $20 \%$ at 13:35 within $1 \mathrm{~h}$ and $25 \mathrm{~min}$. However, the decay of the residual $\mathrm{CO}_{2}\left(\mathrm{CO}_{2}\right.$ left over at the end of releasing) concentration in the soil, shown from the decay curve after the $\mathrm{CO}_{2}$ release, lasted for 


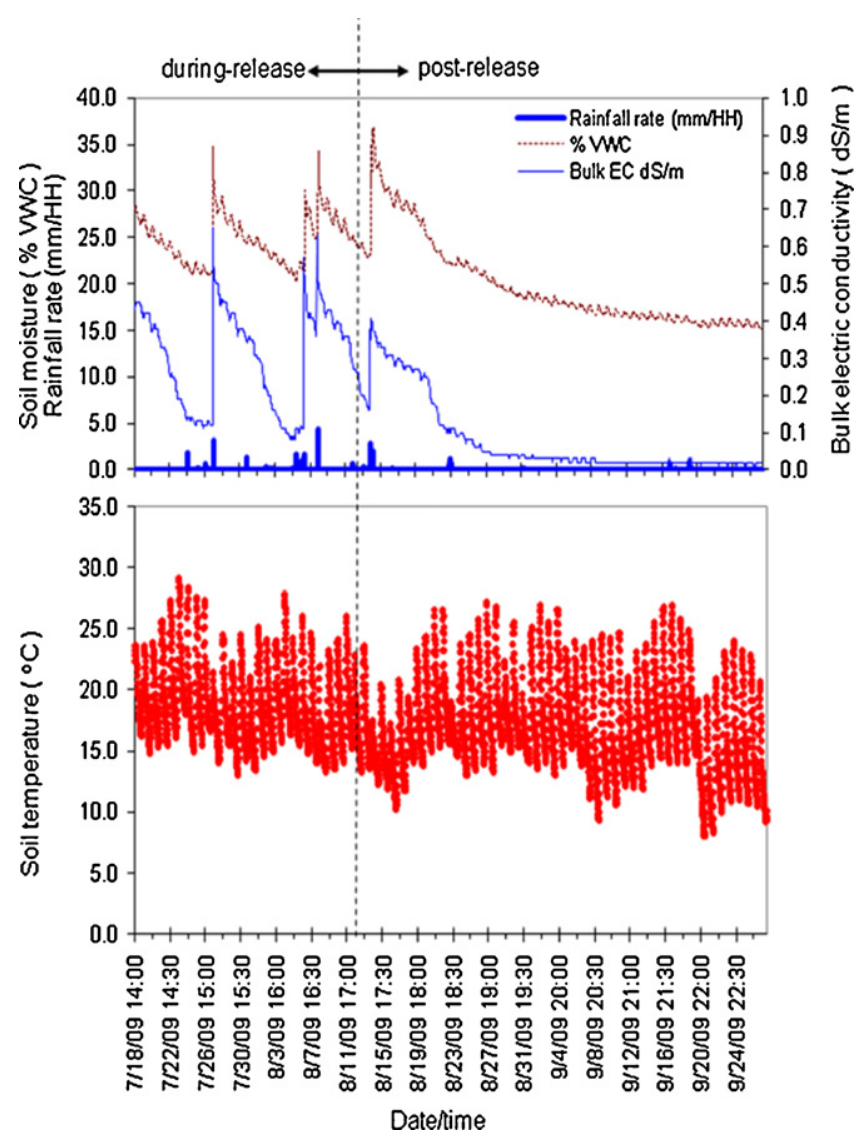

Fig. 3. Temporal variation of soil bulk electrical conductivity, soil moisture, and rainfall rate (top), and soil temperature (bottom). The time period covers both $\mathrm{CO}_{2}$ release period and post-release period. Soil moisture unit is in \%VWC (percent in volume water content) so that soil moisture and rainfall rate can share the same vertical axis. $1 \% \mathrm{VWC}=0.01 \mathrm{~m}^{3} / \mathrm{m}^{3}$.

approximately nine days, from 12:00 pm on August 12, 2009 to $11: 30 \mathrm{pm}$ on August 21,2009 . The average soil $\mathrm{CO}_{2}$ concentration from $00: 00$ on July 2 to $11: 55$ on July 15 is $0.63 \%$, which is taken as the mean background soil $\mathrm{CO}_{2}$ level. For the pre-release period of time, the background soil $\mathrm{CO}_{2}$ concentration varies between $0.18 \%$ and $0.97 \%$.

Fig. 3 shows the time series of the soil electrical conductivity, along with volumetric soil moisture (\%VWC), rainfall rate $(\mathrm{mm} / \mathrm{HH})$, and soil temperature $\left({ }^{\circ} \mathrm{C}\right)$. The sudden increases in soil moisture during and post $\mathrm{CO}_{2}$ release periods are well co-located with rainstorms in time. As the 5TE probe was available only since July 18, 3 days after the start of $\mathrm{CO}_{2}$ release, the period of prior- $\mathrm{CO}_{2}$ release was thus not included. Time periods discussed below include that of $\mathrm{CO}_{2}$ released before 12:00 pm on August 12, 2009 and the period of post $\mathrm{CO}_{2}$ release from 12:00 pm on August 12, 2009 to 9:30 am on September 28, 2009. All data were sampled every $30 \mathrm{~min}$ at a depth of $15 \mathrm{~cm}$. Changes in soil EC and soil moisture are in phase. Corresponding to each rapid increase in soil moisture that was caused by a rainstorm, there was a rapid increase of electrical conductivity. On August 14, rainfall started on about 10 am and did not stop until $11 \mathrm{pm}$ in the night, resulting in a total rainfall of $20 \mathrm{~mm}$ for the day. After August 14 until the end of the field observation (September 29,2009 ), there were two rainfall events: totaling $5.2 \mathrm{~mm} /$ day on August 23 and $1.4 \mathrm{~mm}$ /day on September 20, 2009. However, the rainfall did not infiltrate deep enough to the soil moisture detector and thus the soil moisture was not observed to increase rapidly. From Fig. 2 we can see that after August 14, both the soil moisture and electrical conductivity decreased monotonically with time as a result of evapotranspiration and infiltration.

Various techniques were used to extract information from the time series data. Single variable statistical regression analyses of soil bulk EC with soil $\mathrm{CO}_{2}$ concentration, soil moisture, and soil temperature allows us to look individually at the impact of possible effects of these parameters as single forcing factors in determining the soil EC values. Multivariate analysis of soil bulk EC with all three parameters allows us to look at the synergistic effect of multiple forcings in the determination of soil EC value. To determine if the relationships established through regression analysis are significant, the correlation coefficient $R$ has to be associated to the distribution function $p(R, n)$ that represents the probability that the observed data could have come from an uncorrelated parent population (Williams, 1992), where $R$ is the correlation coefficient, and $n$ is the number of samples. The value of $p(R, n)$ is called the $p$-value. A smaller $p$-value implies that the observed variables are more likely correlated. When $p=0.05$, the correlation is called significant at $95 \%$ level of confidence, which is a common criterion for a significance test.

For linear multivariate analysis, we assume that a multiple linear regression model exists linking bulk soil $\mathrm{EC}$ with soil $\mathrm{CO}_{2}$ concentration, soil moisture and soil temperature and is given as follows (Williams, 1992):

$\sigma=b_{C_{\mathrm{v}} \sigma, \theta_{\mathrm{v}} T} C_{\mathrm{v}}+b_{\theta_{\mathrm{v}} \sigma, C_{\mathrm{v}} T} \theta_{\mathrm{v}}+b_{T \sigma, C_{\mathrm{v}} \theta_{\mathrm{v}}} T+a( \pm S)$

where $\sigma$ is the bulk soil EC in $\mathrm{dS} / \mathrm{m}, a, b_{C_{\mathrm{v}} \sigma, \theta_{\mathrm{v}} T}, b_{\theta_{\mathrm{v}} \sigma, C_{\mathrm{V}} T}, b_{T \sigma, C_{\mathrm{v}} \theta_{\mathrm{v}}}$ are model coefficients, $S$ is the standard error in fitting the model to the observation data, $C_{\mathrm{v}}$ represents the soil $\mathrm{CO}_{2}$ volume concentration in $\%, \theta_{\mathrm{v}}$ is the volumetric soil moisture content $\left(\mathrm{m}^{3} / \mathrm{m}^{3}\right)$, and $T$ is the soil temperature in ${ }^{\circ} \mathrm{C}$. Here soil $\mathrm{CO}_{2}$ concentration, soil moisture and soil temperature are treated theoretically as independent variables because their origins are different and unrelated: soil $\mathrm{CO}_{2}$ concentration is dependent on the $\mathrm{CO}_{2}$ source, especially in the case of leaking sequestered $\mathrm{CO}_{2}$; soil moisture is mainly controlled by rainfall intensity, frequency, duration, and soil infiltration; and soil temperature is mainly controlled by the atmospheric temperature and solar radiation. The statistical significance of the multivariate analyses is tested with an $F$ test (Pearson and Hartley, 1966). The Eq. (1) models the synergetic action among soil $\mathrm{CO}_{2}$ concentration, soil moisture, and soil temperature, assuming that each factor contributes to the bulk soil EC independently and linearly.

\section{Results}

\subsection{Relationship between bulk soil EC and soil $\mathrm{CO}_{2}$ concentration}

During the engineered $\mathrm{CO}_{2}$ leakage experiment (July 15-August $12,2009)$, the $\mathrm{CO}_{2}$ sensor was saturated above the calibration level and the data only indicated that the $\mathrm{CO}_{2}$ volume concentration was above $20 \%$. After termination of the engineered $\mathrm{CO}_{2}$ leakage, the measured soil $\mathrm{CO}_{2}$ concentration dropped within the calibration range of the $\mathrm{CO}_{2}$ sensor (0-20\%) after approximately $8 \mathrm{~h}$. Fig. 4 shows the decay behavior of the soil bulk EC versus the soil $\mathrm{CO}_{2}$ concentration post $\mathrm{CO}_{2}$ release (data above the saturation value were not used in the analysis). As the residual $\mathrm{CO}_{2}$ concentration decreased, the soil bulk EC also decreased. However, rather than a single mode for the relationship between the bulk soil EC and soil $\mathrm{CO}_{2}$ concentration, there are three distinct modes that correspond to three post $\mathrm{CO}_{2}$ release periods. For convenience, Table 1 shows the release and post-release periods, as well as the three soil EC-soil moisture modes after $\mathrm{CO}_{2}$ release. The statistical analysis results are summarized in Table 2 .

The decay mode 1 corresponds to the period of 2 days after ending the gas release during which the soil $\mathrm{CO}_{2}$ concentration decays 
Table 1

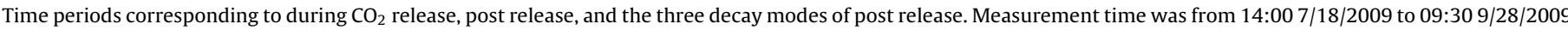

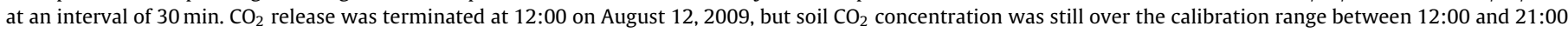
Thus this 9-h period was not included for data analyses.

\begin{tabular}{|c|c|c|c|}
\hline \multirow{2}{*}{$\begin{array}{l}\text { During } \mathrm{CO}_{2} \text { release }(14: 007 / 18 / 2009 \\
\text { to } 12: 008 / 12 / 2009)\end{array}$} & \multicolumn{3}{|c|}{ Post $\mathrm{CO}_{2}$ release (21:00 8/12/2009 to $09: 30$ 9/28/2009) } \\
\hline & $\begin{array}{l}\text { Decay mode } 1 \\
(21: 008 / 12 / 2009 \text { to } 14: 308 / 14 / 2009)\end{array}$ & $\begin{array}{l}\text { Decay mode } 2 \\
(15: 008 / 14 / 2009 \text { to } 11: 308 / 21 / 2009)\end{array}$ & $\begin{array}{l}\text { Decay mode } 3 \\
(12: 008 / 21 / 2009 \text { to } 09: 309 / 28 / 2009)\end{array}$ \\
\hline
\end{tabular}

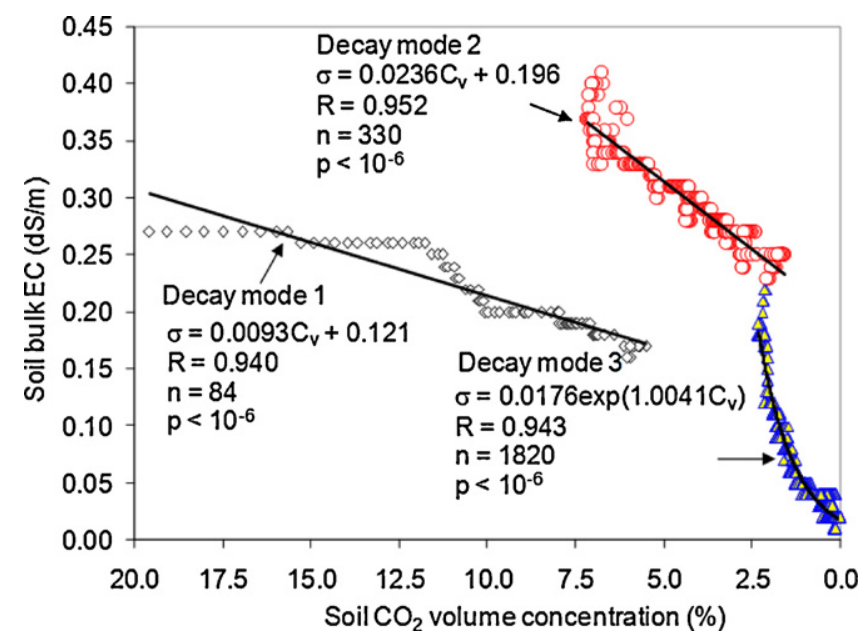

Fig. 4. Soil bulk electrical conductivity (EC) (dS/m) versus soil volumetric $\mathrm{CO}_{2}$ concentration from August 12 to September 28, 2009. Soil $\mathrm{CO}_{2}$ concentration data above the saturation value (20\%) were not used in the regression analysis.

rapidly from above $20 \%$ to about $6 \%$. At the same time, the soil bulk EC decreases by about $47 \%$ from $\sigma=0.27 \mathrm{dS} / \mathrm{m}$ to $0.17 \mathrm{dS} / \mathrm{m}$.

The decay mode 2 occurs during the subsequent seven days (from 15:00 on August 14, 2009 to 11:30 on August 21, 2009). During this period, a rainfall event on August 14, 2009 increased the soil moisture rapidly from $22.9 \%$ to $37.0 \%$ (see Fig. 3). Consequently, the soil EC increased to a maximum of $0.41 \mathrm{dS} / \mathrm{m}$. The soil $\mathrm{CO}_{2}$ concentration also increased from below $6 \%$ to a maximum of $7.2 \%$ on August 15 during this stage. The rainfall event caused the degree of saturation to increase because of the increase of soil moisture, reducing the equivalent diffusion porosity (Aachib et al., 2004). On the other hand, the diffusion coefficient of $\mathrm{CO}_{2}$ through air is $10^{4}$ times higher than that through liquid water (Luo and Zhou, 2006). The effective gas diffusion coefficient through soil decreases with increasing degree of saturation (Aachib et al., 2004). In other words, the high moisture content at the top layer of soil following a rainfall blocks the $\mathrm{CO}_{2}$ from escaping through the ground surface. Therefore, $\mathrm{CO}_{2}$ gas concentration increased following the rainfall event on August 14, 2009, which played a main role in bifurcating the first and second decay modes. The overall time taken for the first two decay modes to be completed was about 7 days. The first decay mode is due to the decrease of soil $\mathrm{CO}_{2}$ caused by the diffusion of $\mathrm{CO}_{2}$ from soil to atmosphere. The appearance of decay mode 2 is due to the combined effects of the rainfall on August 14 and the high

\section{Table 2}

The statistical results for the three post- $\mathrm{CO}_{2}$ release modes for the relationship between soil bulk EC and soil $\mathrm{CO}_{2}$ concentration ( $R$ : correlation coefficient; $R^{2}$ : determination coefficient, $n$ : sampling size, $p$ : significance level).

\begin{tabular}{llll}
\hline & Decay mode 1 & Decay mode 2 & Decay mode 3 \\
\hline$R$ & 0.940 & 0.952 & 0.943 \\
$R^{2}$ & 0.884 & 0.906 & 0.889 \\
$n$ & 84 & 330 & 1820 \\
$p$ & $<10^{-6}$ & $<10^{-6}$ & $<10^{-6}$ \\
Duration & August 12-14, & August 14-21, & August 21- \\
& 2009 & 2009 & September 28, 2009 \\
\hline
\end{tabular}

residual soil $\mathrm{CO}_{2}$ that is much higher than the background $\mathrm{CO}_{2}$ level ( $0.63 \%$ on average, see Section 3$)$.

The decay mode 3 , (Tables 1 and 2), corresponds to the time period (about 38 days) between 11:30 on August 21, 2009 and 09:30 on September 28, 2009 (the end of observations). The relationship between the bulk soil EC and the soil $\mathrm{CO}_{2}$ concentration does not follow the pattern of the decay mode 2 , but instead, the soil moisture at the end of the second mode decreased to a certain level at which the residual $\mathrm{CO}_{2}$ migrated out of soil at a higher speed because the effective diffusion coefficient of $\mathrm{CO}_{2}$ increases as the soil moisture drained with time. With time, the residual soil $\mathrm{CO}_{2}$ dropped gradually to the mean background $\mathrm{CO}_{2}$ level before $\mathrm{CO}_{2}$ release at 22:40 on August 28, 2009.

\subsection{Relationship between bulk soil EC and soil moisture}

The bulk soil EC is affected by the properties of both the solid and liquid phases in the soil. To investigate the relationship between bulk soil EC $(\sigma)$ and soil moisture in volume $\left(\theta_{\mathrm{v}}\right)$ quantitatively, Fig. 5 shows the scatter plot of bulk soil EC versus soil moisture, along with the results from the statistical analysis for the entire measurement period from July 18, 2009 to September 28, 2009 at an interval of $30 \mathrm{~min}$. We can see from Fig. 5 that the data points of the first two days (August 12-August 14) immediately after the engineered $\mathrm{CO}_{2}$ leakage was terminated at 12:00 pm on August 12 separate well from the other post release data points and fall within the during-release data points. To see the impact of $\mathrm{CO}_{2}$ leakage on the soil EC-moisture relationship, the data were divided to two groups for the purpose of regression analyses: high soil $\mathrm{CO}_{2}$ group (July 18-August 14) and low soil $\mathrm{CO}_{2}$ group (August 14-September 28 ). Since the soil $\mathrm{EC}$ and soil $\mathrm{CO}_{2}$ volume concentration data points for the decay mode 1 overlap with the during-release data points

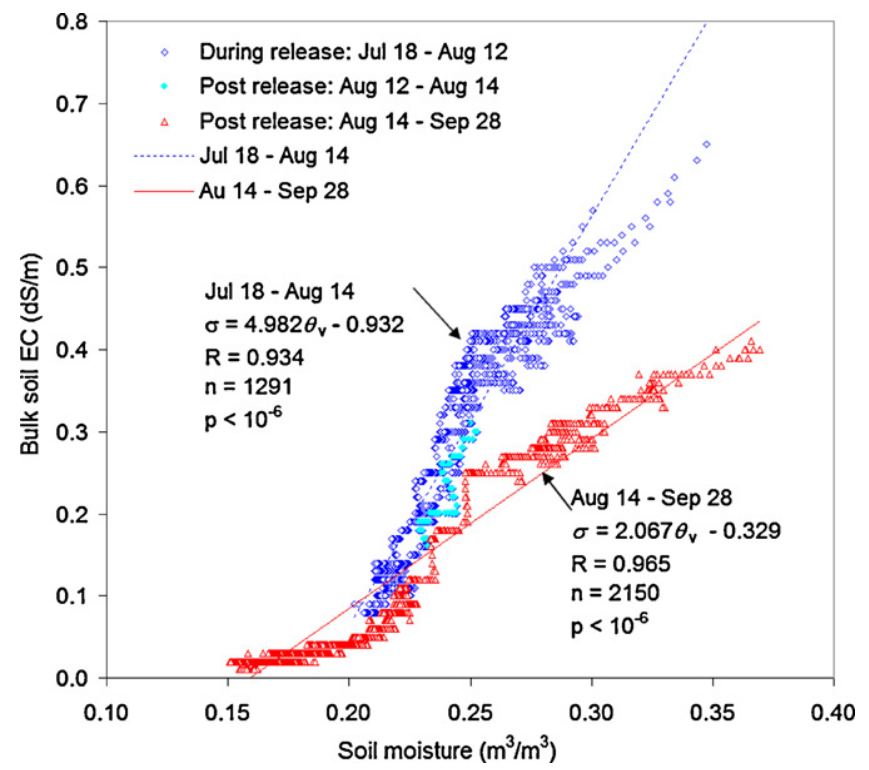

Fig. 5. Soil bulk electrical conductivity $(\mathrm{EC})(\mathrm{dS} / \mathrm{m})$ versus volumetric soil moisture from July 18 to September 28, 2009. 
and have a similar trend (Fig. 4), EC-moisture data points for the decay mode 1 were thus included in the first group. In total, there are $n=1291$ data points of bulk soil EC and soil moisture for the high soil $\mathrm{CO}_{2}$ group (period of engineered $\mathrm{CO}_{2}$ leakage and the first two days after the release was terminated) and $n=2150$ data points for the low soil $\mathrm{CO}_{2}$ group (August 14 to September 28 of post release). The $\sigma-\theta_{\mathrm{v}}$ relationship during the $\mathrm{CO}_{2}$ release is completely different from those of the post-release. The two trend lines crossed over at a soil moisture content of about $0.21 \mathrm{~m}^{3} / \mathrm{m}^{3}$. With soil moisture above $0.21 \mathrm{~m}^{3} / \mathrm{m}^{3}$, when there is $\mathrm{CO}_{2}$ leakage and the soil $\mathrm{CO}_{2}$ is high the bulk soil EC value is higher than when there is little or no $\mathrm{CO}_{2}$ leakage, and the difference increases with increasing soil moisture. Liquid water in the soil provides an agent for solution of ions in the soil. During the entire $72 \mathrm{~d}$ period of observation, from July 18 to September 28,2009, the bulk soil EC varied between 0.01 and $0.65 \mathrm{dS} / \mathrm{m}$, and increased with increasing soil moisture. Increase of soil EC with increasing soil moisture was also observed by others (McCarter, 1984; Fukue et al., 1999; Michot et al., 2003). This observation under the open field conditions is different from the speculation that increasing soil moisture will dilute the solute salt concentration and thus reduce the bulk soil EC based on laboratory work on soil samples (Adviento-Borbe et al., 2006), indicating the in situ availability and dynamics of soluble salts when soil water content varies.

Electrical conduction of soil is mainly electrolytic that is based on the movement of mobile ions in soil water. Therefore greater dissolved salts will result in larger soil EC. Thus, soil EC depends on the amount of water in the pores and the dissolved amount of salts (Samouëlian et al., 2005). Dissolution of $\mathrm{CO}_{2}$ in the soil water enhances the dependence of the bulk EC on soil moisture. This is because carbonic acids associated with the dissolution of $\mathrm{CO}_{2}$ in the soil water enhance mineral dissolution of the aquifer materials; a similar process as occurs with organic acids (McMahon et al., 1995). Also, the increase in carbonate and bicarbonate ions themselves due to $\mathrm{CO}_{2}$ dissolution can also cause a direct increase in the EC. Therefore, the ways the soil bulk EC depends on soil moisture are different as is shown by the two distinct trends in Fig. 5 .

\subsection{Relationship between soil bulk EC and soil temperature}

Fig. 6 shows the dependence of bulk soil EC on soil temperature, which compared with that of soil moisture is weaker but still significant. Physically it is expected that the soil EC depends on the temperature since the solubility of salts and $\mathrm{CO}_{2}$ in soil water depends on water temperature. However, the dependence of the solubility of $\mathrm{CO}_{2}$ on temperature in soil water is weak. This weak dependence can be seen from the small correlation coefficient values $(-0.248$ and -0.100$)$ and model coefficient of the temperature dependence $\left(9.4 \times 10^{-3}\right.$ and $2.4 \times 10^{-3}$, respectively) of soil bulk electrical conductivity $(\mathrm{dS} / \mathrm{m})$ for during-release period and postrelease period in Fig. 6, where we can also see that the soil bulk EC decreases with increasing temperature. This observation is consistent with the fact that solubility of carbon dioxide decreases with increasing water temperature when pressure is constant (Wiebe and Gaddy, 1940; Carroll et al., 1991). When dissolved in water, $\mathrm{CO}_{2}$ forms weak bonds with the water molecules. The lower the temperature, the stronger the bonds, the greater the amount of $\mathrm{CO}_{2}$ that can be dissolved. For the whole range of temperature $\left(13.0-29.1^{\circ} \mathrm{C}\right)$ during release, the change range of bulk soil EC resulted from temperature change can possibly be $0.15 \mathrm{dS}$. For the period of low $\mathrm{CO}_{2}$ concentration (from 2 days' data after release until the end of the field experiment on September 28, 2009), the slope is reduced to $0.0024 \mathrm{dS} /{ }^{\circ} \mathrm{C}$. For the whole range of temperature $\left(8.0-27.2^{\circ} \mathrm{C}\right)$ post release, the change range of soil EC resulting from temperature change can possibly be $0.034 \mathrm{dS}$.
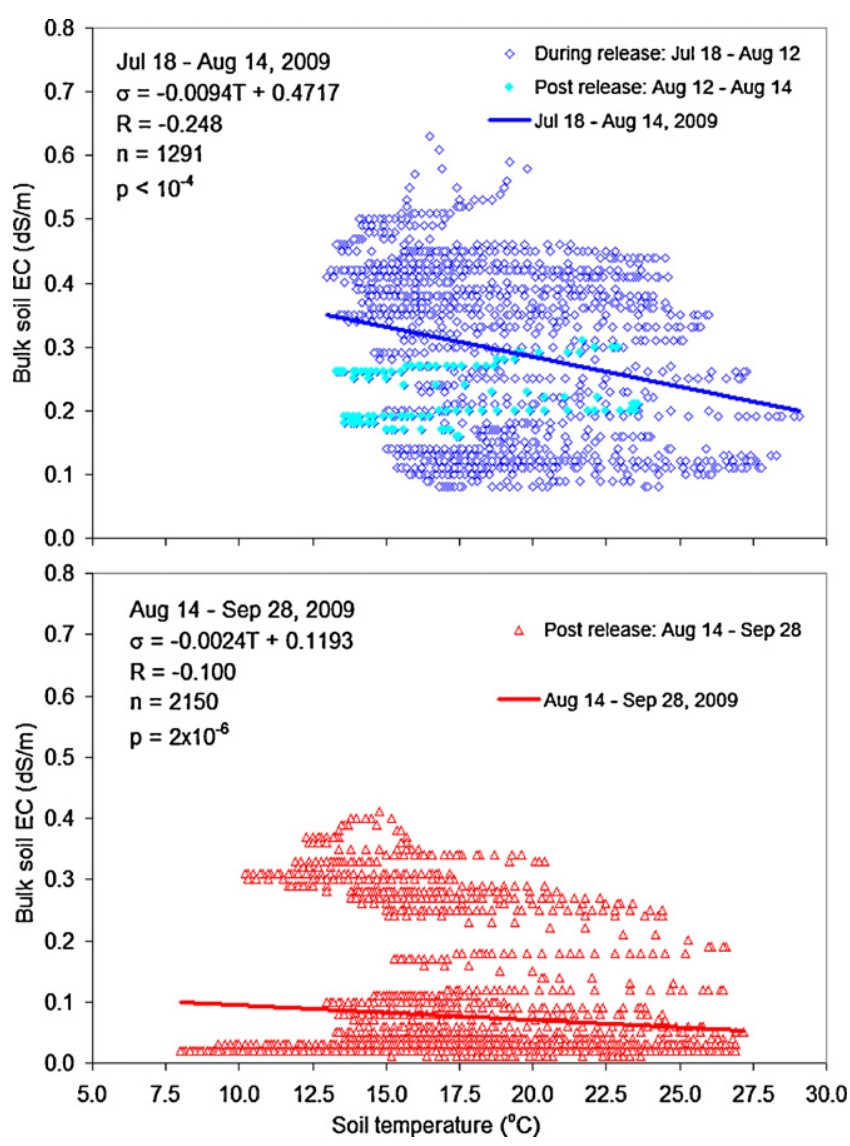

Fig. 6. Soil bulk electrical conductivity $(\mathrm{EC})(\mathrm{dS} / \mathrm{m})$ versus soil temperature $\left({ }^{\circ} \mathrm{C}\right)$ for during-release period (top) and post-release period (bottom) of engineered $\mathrm{CO}_{2}$ leakage from July 18 to September 28, 2009.

\subsection{Soil bulk EC as a function of soil $\mathrm{CO}_{2}$ concentration, soil moisture, and soil temperature}

To quantify the synergic impact of soil moisture, temperature, and soil $\mathrm{CO}_{2}$ volume concentration on bulk soil $\mathrm{EC}$, let us use the linear model (Eq. (1)) and find the model coefficients. To separate the impacts of $\mathrm{CO}_{2}$ release and the impact after $\mathrm{CO}_{2}$ release, we subdivided the whole measurement period into two: during $\mathrm{CO}_{2}$ release (July 18-August 12 ) and post- $\mathrm{CO}_{2}$ release (August 12 -September 28).

Because the measured $\mathrm{CO}_{2}$ concentration was over the calibrated range for the duration of the $\mathrm{CO}_{2}$ release (July 18-August $12,1999)$, analyses were performed only for the soil EC with soil moisture and soil temperature. Results show that a multivariate linear model of soil bulk EC with soil moisture and soil temperature exists and is given as follows:

$\sigma=4.859 \theta_{\mathrm{v}}-0.008 T-0.741( \pm 0.0375) \quad\left(\mathrm{CO}_{2}\right.$ release phrase $)(2)$

The statistics (multiple correlation coefficient, determination coefficient, sample size, significance level, standard error, etc.) are shown in Table 3, along with the value range for each parameter from which Eq. (2) was derived. The multivariate linear regression relation (2) is significant to $100.0 \%$ level of confidence for fitting the field data sets. In Eq. (2), the units for $\sigma, \theta_{\mathrm{v}}$, and $T$ are $\mathrm{dS} / \mathrm{m}, \mathrm{m}^{3} / \mathrm{m}^{3}$ in volume, and ${ }^{\circ} \mathrm{C}$, respectively. Although the soil $\mathrm{CO}_{2}$ concentration has not been incorporated into the multivariate regression model because the measured values are over the calibrated range, the implicit impact of $\mathrm{CO}_{2}$ on the soil EC is imbedded in the EC-soil moisture relation. Since soil moisture provides a solvent for the solutes that is enhanced by the dissolution of $\mathrm{CO}_{2}$, increase of the 
Table 3

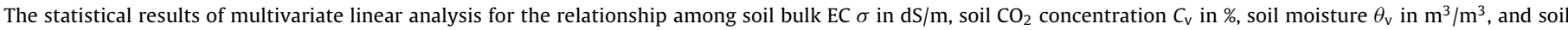

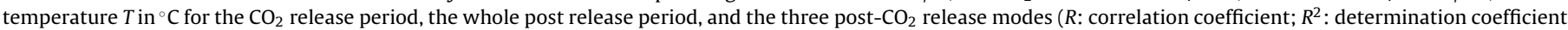

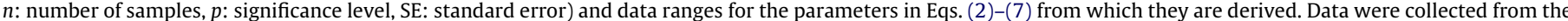
2009 field experiment.

\begin{tabular}{|c|c|c|c|c|c|c|}
\hline & \multirow{2}{*}{$\begin{array}{l}\text { During release } \\
\left(\mathrm{CO}_{2} \text { excluded }\right)\end{array}$} & \multirow{2}{*}{$\begin{array}{l}\text { Post release } \\
\left(\mathrm{CO}_{2} \text { excluded }\right)\end{array}$} & \multicolumn{4}{|c|}{ Post release $\left(\mathrm{CO}_{2}\right.$ included $)$} \\
\hline & & & Post release & Decay mode 1 & Decay mode 2 & Decay mode 3 \\
\hline Equation & $(2)$ & (3) & (4) & (5) & (6) & (7) \\
\hline$R$ & 0.960 & 0.969 & 0.976 & 0.988 & 0.984 & 0.938 \\
\hline$R^{2}$ & 0.922 & 0.939 & 0.953 & 0.976 & 0.968 & 0.880 \\
\hline$N$ & 1190 & 2234 & 2234 & 84 & 330 & 1820 \\
\hline$P$ & $<10^{-6}$ & $<10^{-6}$ & $<10^{-6}$ & $<10^{-6}$ & $<10^{-6}$ & $<10^{-6}$ \\
\hline SE & \pm 0.0375 & \pm 0.0253 & \pm 0.0221 & \pm 0.0057 & \pm 0.007 & \pm 0.0118 \\
\hline$\sigma$ & $0.08-0.65$ & $0.01-0.41$ & $0.01-0.41$ & $0.16-0.27$ & $0.23-0.41$ & $0.01-0.22$ \\
\hline$C_{\mathrm{V}}$ & Excluded & Excluded & $0.02-19.06$ & $5.5-19.6$ & $1.6-7.2$ & $0.02-2.33$ \\
\hline$\theta_{\mathrm{v}}$ & $0.200-0.350$ & $0.150-0.370$ & $0.150-0.370$ & $0.229-0.245$ & $0.248-0.370$ & $0.15-0.25$ \\
\hline$T$ & 13.0-29.1 & $8.0-27.2$ & $8.0-27.2$ & $13.3-23.6$ & $10.2-24.4$ & $8.0-27.2$ \\
\hline Duration & $7 / 18-8 / 12$ & $8 / 12-9 / 28$ & $8 / 12-9 / 28$ & $8 / 12-8 / 14$ & $8 / 14-8 / 21$ & $8 / 21-9 / 28$ \\
\hline
\end{tabular}

bulk soil EC is thus proportional to the soil water content. While on the other hand, since the solubility of $\mathrm{CO}_{2}$ and solutes from soil in the soil liquid water decreases with temperature, the bulk soil EC thus decreases as the soil temperature increases. The data ranges from which Eq. (2) is derived are: soil moisture $\theta_{\mathrm{v}}$ varies from 0.20 to $0.35 \mathrm{~m}^{3} / \mathrm{m}^{3}$, soil temperature varies from 13.0 to $29.1^{\circ} \mathrm{C}$, and the soil bulk EC $\sigma$ varies from 0.08 to $0.65 \mathrm{dS} / \mathrm{m}$. The number of samples is 1190 .

A multivariate linear regression analysis similar to Eq. (2) but for the post-release period of time (August 12-September 28, 1999) was also performed to investigate the difference in the response of bulk soil EC to the soil moisture and soil temperature between during-release and post-release periods. Results show that a multivariate linear model of soil bulk EC with soil moisture and soil temperature also exists for post-release and is given as follows

$$
\begin{aligned}
\sigma= & 2.111 \theta_{\mathrm{v}}-0.003 T-0.283( \pm 0.0253) \\
& \left(\text { post }-\mathrm{CO}_{2}\right. \text { release phrase) }
\end{aligned}
$$

with the multiple correlation coefficient $R=0.969$, standard error of \pm 0.0253 . The regression relation (3) is significant to $100.0 \%$ level of confidence for fitting the field data sets. The statistics for the above regression analysis are also shown in Table 3. A comparison with Eq. (2) shows that the model coefficient for soil moisture was reduced from $4.589 \mathrm{dS}$ for $\mathrm{CO}_{2}$ release phase to $2.111 \mathrm{dS}$ for post $\mathrm{CO}_{2}$ release phase; that for temperature was reduced from 0.008 to $0.003 \mathrm{dS} /{ }^{\circ} \mathrm{C}$. This may indicate that high soil $\mathrm{CO}_{2}$ concentration due to $\mathrm{CO}_{2}$ leakage enhances the dependence of soil bulk EC on soil moisture and soil temperature.

From Fig. 4 we have seen that the entire post $\mathrm{CO}_{2}$-release period can be divided into three sub-periods, corresponding to the three modes of the soil bulk EC-soil volume $\mathrm{CO}_{2}$ concentration $\left(\theta_{\mathrm{v}}\right)$ scatter plot. As the measured $\mathrm{CO}_{2}$ values are within the range of calibration, it is possible to perform the multivariate analysis for the bulk soil EC with soil moisture, temperature and $\mathrm{CO}_{2}$ concentration. Firstly, let us perform a multivariate linear analysis for the whole post $\mathrm{CO}_{2}$-release period (August 12-September 29, 2009) without identifying distinct decay modes. This gives the bulk soil EC as a function of $\mathrm{CO}_{2}$ concentration $C_{\mathrm{v}}$, soil moisture $\theta_{\mathrm{v}}$, and temperature $T$ :

$\sigma=0.008 C_{v}+1.824 \theta_{v}-0.003 T-0.243( \pm 0.0221)$

(post $\mathrm{CO}_{2}$ release phase)
Then, multivariate linear analyses are performed separately for each of the sub-periods corresponding to each mode (Fig. 4). The bulk soil EC was found to be significantly correlated with $\mathrm{CO}_{2}$ concentration $C_{\mathrm{v}}$, soil moisture $\theta_{\mathrm{v}}$, and temperature $T$ for each of the sub-periods:

$$
\sigma=0.002 C_{\mathrm{v}}+6.055 \theta_{\mathrm{v}}-0.008 T-1.108( \pm 0.0057)
$$

(decay mode 1 )

$\sigma=0.007 C_{\mathrm{V}}+0.952 \theta_{\mathrm{v}}-0.003 T+0.041( \pm 0.007)$

(decay mode 2)

$\sigma=0.048 C_{\mathrm{V}}+0.227 \theta_{\mathrm{v}}-0.001 T-0.017( \pm 0.0118)$

(decay mode 3 )

The statistics (multiple correlation coefficient, determination coefficient, sample size, significance level, standard error, etc.) of these empirical relationships (Eqs. (4)-(7)) are shown in Table 3, along with the value range for each parameter from which they were derived. For all post- $\mathrm{CO}_{2}$ release relationships, the significance is always at the $100.0 \%$ level of confidence. A comparison between Eqs. (3) and (4) shows that inclusion of soil $\mathrm{CO}_{2}$ concentration in the multivariate analysis reduces the dependence of bulk soil EC on the soil moisture from 2.111 to $1.824 \mathrm{dS}$, while has no impact on the dependence of the bulk soil EC on the soil temperature (coefficient $0.003 \mathrm{dS} /{ }^{\circ} \mathrm{C}$ for both cases). Comparing Eq. (2) with Eq. (5), we can see that the derived dependence of bulk soil EC on the soil temperature is exactly the same during the $\mathrm{CO}_{2}$ release and during the decay mode 1 . This may indicate the role played by soil temperature in contributing to the soil bulk EC in the first 2 days after release termination is the same as the releasing period since the soil $\mathrm{CO}_{2}$ concentration was still very high for the first two days after termination of release.

Soil is a complex medium consisting of a broad range of types of mineral particles and aggregates, organic constituents, and numerous organisms exhibiting different physiological processes. As $\mathrm{CO}_{2}$ gas leaks into the soil, it dissolves into the pore water, thereby decreasing $\mathrm{pH}$ while at the same time promoting dissolution of such minerals as calcite, dolomite, sulfide, siderite, ferrihydrite, and iron oxyhydroxides present in soil (West et al., 2009; Kharaka et al., 2010). $\mathrm{CO}_{2}$-rich pore water will change the dynamics of common soil salts in many agricultural soils $\left(\mathrm{Al}^{3+}, \mathrm{Ca}^{2+}, \mathrm{Cl}^{-}, \mathrm{CO}_{3}{ }^{2-}, \mathrm{H}^{+}\right.$, $\mathrm{HCO}_{3}{ }^{-}, \mathrm{K}^{+}, \mathrm{Mg}^{2+}, \mathrm{Na}^{+}, \mathrm{NO}_{3}{ }^{2+}, \mathrm{HO}^{-}$, etc.) and enhance soil salinity (Liu et al., 2006; Carroll et al., 2009; Eigenberg et al., 2010). 
Increased soil acidity due to dissolved $\mathrm{CO}_{2}$ can cause simultaneous dissolution and desorption of many elements in soil water (Wang and Jaffe, 2004; Zheng et al., 2009). It was found that a wide range of metals could be desorbed from the iron hydroxides common in sedimentary rocks as the $\mathrm{pH}$ is reduced from ambient conditions in response to leaking $\mathrm{CO}_{2}$ (Kharaka et al., 2006). Metal ion concentrations in water can be modeled as desorption cation-exchange process which would impact the soil bulk EC (Birkholzer et al., 2008; Zheng et al., 2009).

Since soil electrical conduction is mainly through electrolytes, i.e., soil EC is mainly based on the displacement of ions in porewater, and it is therefore greater with the presence of dissolved salts (Samouëlian et al., 2005). During the first 2 days after the $\mathrm{CO}_{2}$ release was turned off, soil $\mathrm{CO}_{2}$ concentration decreased rapidly from $19.6 \%$ to $5.5 \%$ (see Fig. 2). Temperature dependence of the solubility of $\mathrm{CO}_{2}$ in soil moisture during this stage is not different than the $\mathrm{CO}_{2}$-releasing period. However, the higher the soil $\mathrm{CO}_{2}$ concentration, the greater the dissolved $\mathrm{CO}_{2}$ concentration in the soil water. At the same time, the greater the soil moisture is, the more the dissolved $\mathrm{CO}_{2}$ and salts in the soil water solution are, and the higher the soil bulk EC is. It is thus expected that the soil bulk $\mathrm{EC}$ is proportional to soil $\mathrm{CO}_{2}$ concentration and soil moisture, as is shown in Eq. (5).

The electrical conductivity of a soil is determined by soil clay content, soil moisture, total soil salinity, soil salt composition, electrophoretic mobility, and temperature (Liu et al., 2006). In particular, soil water content influences soil EC through the concentration of dissolved ions in the soil. Soluble salt concentrations in soils are thus widely measured in terms of EC (Rhoades, 1993; Smith and Doran, 1996; Rhoades et al., 1999). Let us examine the model coefficient of each independent variable $\theta_{\mathrm{v}}, T$, and $C_{\mathrm{v}}$ within Eqs. (5)-(7). When the relationship between soil bulk EC and soil $\mathrm{CO}_{2}$ concentration $\theta_{\mathrm{v}}$ evolves with time from the decay mode 1 (Eq. (5)) to the decay mode 2 (Eq. (6)), the dependence of soil bulk EC on soil moisture and soil temperature decreases, while that on soil $\mathrm{CO}_{2}$ concentration increases. In both decay modes, we can see that the soil-water effect on the bulk soil conductivity is the dominant factor. For instance, for the decay mode 1 , a $1 \%$ change in soil $\mathrm{CO}_{2}$ concentration can result in a change of $0.002 \mathrm{dS} / \mathrm{m}$ in soil EC, while $1 \%$ change in soil moisture will result in a change of $0.061 \mathrm{dS}$ in soil EC. After the decay mode 1 , soil $\mathrm{CO}_{2}$ concentration decreases much more slowly from $7.2 \%$ to $1.6 \%$ within 7 days. The coefficient of the soil $\mathrm{CO}_{2}$ concentration $\theta_{\mathrm{v}}$ increases from 0.002 to 0.007 (unit: $\mathrm{dS} / \mathrm{m} \%$ ). Since the soil $\mathrm{CO}_{2}$ concentration is much lower than in the decay mode 1 , enhanced concentration of dissolved ions in the soil moisture due to the dissolved $\mathrm{CO}_{2}$ is reduced, as is the dissolved $\mathrm{CO}_{2}$ due to temperature. As a result, the dependence of soil bulk EC on soil moisture and soil temperature decreases.

Similar phenomena occur when the relationship between soil bulk EC and soil $\mathrm{CO}_{2}$ concentration $\theta_{v}$ evolves with time from the decay mode 2 (Eq. (6)) to the decay mode 3 (Eq. (7)): the dependence of soil bulk EC on soil moisture and soil temperature decreases further, while that on soil $\mathrm{CO}_{2}$ concentration increases. After the decay mode 2 , soil $\mathrm{CO}_{2}$ concentration decreases even more slowly from $2.33 \%$ to $0.02 \%$ within 38 days. Compared with the decay mode 2 (Eq. (6)), an even higher percentage of soil $\mathrm{CO}_{2}$ concentration is dissolved and thus it is more effective in affecting the soil bulk EC. Consequently, the coefficient of the soil $\mathrm{CO}_{2}$ concentration $\theta_{\mathrm{v}}$ increases from 0.007 to 0.048 (unit: $\mathrm{dS} / \mathrm{m} \%$ ). For a similar reason as in the transition from the decay mode 1 to the decay mode 2 , the dependence of soil bulk EC on soil moisture and soil temperature further decreases when the soil $\mathrm{CO}_{2}$ enters into mode 3 . In considering the dependence of bulk soil EC on the soil temperature, the low correlation coefficient between EC and temperature may indicate that the temperature is a secondary effect.

\section{Discussion and conclusions}

This study focuses on the $\mathrm{CO}_{2}$-driven alteration of soil microenvironment and subsequent changes in soil EC by subsurface $\mathrm{CO}_{2}$ release to simulate leakage of sequestered $\mathrm{CO}_{2}$. In general, water content appeared to be the most important factor that influenced EC (Rhoades et al., 1999). However, carbon dioxide is soluble in soil water and forms a pH-dependant balance of several ionic and non-ionic species that are collectively called dissolved inorganic carbon. These species include carbonic acid $\left(\mathrm{H}_{2} \mathrm{CO}_{3}\right)$, bicarbonate $\left(\mathrm{HCO}_{3}{ }^{-}\right)$and carbonate $\left(\mathrm{CO}_{3}{ }^{2-}\right)$, which increase soil EC. The dissolution of $\mathrm{CO}_{2}$ in soil water can be described by the following reactions (Lindsay, 1979; Rasmuson et al., 1990): $\mathrm{CO}_{2}+\mathrm{H}_{2} \mathrm{O} \Leftrightarrow$ $\mathrm{H}_{2} \mathrm{CO}_{3} \Leftrightarrow \mathrm{H}^{+}+\mathrm{HCO}_{3}{ }^{-} \Leftrightarrow 2 \mathrm{H}^{+}+\mathrm{CO}_{3}{ }^{2-}$. The solubility of carbon dioxide is dependent on factors such as $\mathrm{pH}$, which is regulated by the charge balance of a number of positive (e.g. $\mathrm{Al}^{3+}, \mathrm{H}^{+}, \mathrm{Na}^{+}$, $\mathrm{K}^{+}, \mathrm{Mg}^{2+}, \mathrm{Ca}^{2+}$ ) and negative (e.g. $\mathrm{CO}_{3}{ }^{2-}, \mathrm{HCO}_{3}{ }^{-}, \mathrm{Cl}^{-}, \mathrm{NO}_{3}{ }^{2-}, \mathrm{HO}^{-}$, $\mathrm{SO}_{4}{ }^{2-}$,) ions in the soil (Liu et al., 2006). The groundwater samples from $1.5 \mathrm{~m}$-deep wells at this research site showed a rapid and systematic decrease in $\mathrm{pH}$, an increase in anion $\mathrm{HCO}_{3}{ }^{-}$, and major increases in the concentrations of cations $\mathrm{Ca}^{2+}, \mathrm{Mg}^{2+}, \mathrm{Fe}^{3+}$, and $\mathrm{Mn}^{2+}$ following $\mathrm{CO}_{2}$ injection (Kharaka et al., 2010). Dissolution of observed carbonate minerals and desorption ion exchange resulting from lowered $\mathrm{pH}$ values following $\mathrm{CO}_{2}$ injection are the likely geochemical processes responsible for the observed increases in the concentrations of solutes. High ionic concentrations can be caused by $\mathrm{CO}_{2}$ dissolution and geochemical reactions along the seepage paths of sequestered $\mathrm{CO}_{2}$. For instance, calcium carbonate and magnesium carbonate in soil can be dissolved along the following pathways: $\mathrm{CaCO}_{3}+\mathrm{CO}_{2}+\mathrm{H}_{2} \mathrm{O} \rightarrow \mathrm{Ca}^{2+}+2\left(\mathrm{HCO}_{3}\right)^{-}$and $\mathrm{MgCO}_{3}+\mathrm{CO}_{2}+\mathrm{H}_{2} \mathrm{O} \rightarrow \mathrm{Mg}^{2+}+2\left(\mathrm{HCO}_{3}\right)^{-}$. These reactions can be enhanced by biological regeneration in soils (Raven and Falkowski, 1999). Although the solubility of $\mathrm{CO}_{2}$ in water is small (Enick and Klara, 1990), the apparent different behaviors of EC-soil moisture with and without $\mathrm{CO}_{2}$ leaking indicates that the impact of the solution of this small amount of $\mathrm{CO}_{2}$ in soil water has seemingly manifested itself well in the soil EC-soil moisture relationship. The soil bulk conductivity increase caused by dissolution of $\mathrm{CO}_{2}$ in the soil water observed in this study is different from the case in which $\mathrm{CO}_{2}$ is not dissolved in water during the $\mathrm{CO}_{2}$ injection into deep saline aquifer where replacement of the saline brine in the rock matrix by $\mathrm{CO}_{2}$ plume causes the apparent conductivity to decrease (Kiessling et al., 2010).

From Fig. 4 we can see that the decay of residual $\mathrm{CO}_{2}$ in soil after termination of $\mathrm{CO}_{2}$ release evolves in three different modes. For the first 2 days immediately after release, soil $\mathrm{CO}_{2}$ concentration was still very high (5.5-19.6\%). The $\mathrm{CO}_{2}$ trapped in the soil migrates to the surface and eventually enters the atmosphere. Such diffusion of $\mathrm{CO}_{2}$ from soil to atmosphere reduces the soil $\mathrm{CO}_{2}$ from $19.6 \%$ to $5.5 \%$ within 2 days. The soil $\mathrm{CO}_{2}$ partial pressure decreased with decreases of soil $\mathrm{CO}_{2}$ concentration. From Henry's law, the solubility of $\mathrm{CO}_{2}$ in water at a constant temperature decreases when the $\mathrm{CO}_{2}$ partial pressure decreases (Wiebe and Gaddy, 1940; Carroll et al., 1991), a decrease in the soil $\mathrm{CO}_{2}$ concentration or partial pressure results in a decrease in the dissolved $\mathrm{CO}_{2}$ in soil water, causing a reduction in soil bulk EC.

A rainfall event on Aug 24, 2009 jump started the decay mode 2. Increasing degree of saturation in the topsoil reduced $\mathrm{CO}_{2}$ diffusion because the diffusion coefficient of $\mathrm{CO}_{2}$ through liquid water is $10^{4}$ times lower than that through air (Luo and Zhou, 2006), causing the soil $\mathrm{CO}_{2}$ concentration to rise to $7.2 \%$ from $5.5 \%$; soil $\mathrm{CO}_{2}$ concentration then decreases slowly from $7.2 \%$ to $1.6 \%$ within 7 days. Compared with the decay mode 1 (Eq. (5)), retention time for soil $\mathrm{CO}_{2}$ was relatively longer. This may suggest that the soil $\mathrm{CO}_{2}$ in decay mode 2 would have longer time to dissolve in the soil water to establish the equilibrium in the following 
processes: $\quad \mathrm{CO}_{2}$ (gas) $\Leftrightarrow \mathrm{CO}_{2}$ (liquid) and $\mathrm{CO}_{2}$ (liquid) + $\mathrm{H}_{2} \mathrm{O}$ (liquid) $\Leftrightarrow 2 \mathrm{H}^{+}+\mathrm{CO}_{3}{ }^{2-}$ (solution), resulting in a higher percentage of soil $\mathrm{CO}_{2}$ concentration dissolved in the soil water. This suggestion is consistent with the observation that the model coefficient of $\mathrm{CO}_{2}$ increases from $0.002 \mathrm{dS} / \mathrm{m} \%$ for decay mode 1 to $0.007 \mathrm{dS} / \mathrm{m} \%$ for decay mode 2 . Since $\mathrm{CO}_{2}$ in gas phase will not conduct, its impact on soil bulk EC must go through dissolution and ionization. Soil moisture should be more important than lithologic conditions in soil since increase in soil EC due to $\mathrm{CO}_{2}$ leakage is mainly due to the dissolution of $\mathrm{CO}_{2}$ in soil moisture. In certain wet conditions, we may reasonably expect $\mathrm{CO}_{2}$ decay modes to occur at other sites than the ZERT site when the residual soil $\mathrm{CO}_{2}$ concentration from leakage is still high and a sudden increase in soil moisture caused by rainfall events occurs.

For the $\mathrm{CO}_{2}$ decay mode 3 of post $\mathrm{CO}_{2}$ release or the final stage of observation (August 21-September 28), the residual soil $\mathrm{CO}_{2}$ dropped gradually from $2.33 \%$ to the background $\mathrm{CO}_{2}$ level that was generated by root and soil microbial respiration. Compared with the decay modes 1 and 2 (Eqs. (5)-(6)), retention time for soil $\mathrm{CO}_{2}$ was even longer, resulting in an even higher percentage of soil $\mathrm{CO}_{2}$ concentration dissolved in the soil water. The model coefficient of $\mathrm{CO}_{2}$ increases from $0.007 \mathrm{dS} / \mathrm{m} \%$ for decay mode 2 to $0.048 \mathrm{dS} / \mathrm{m} \%$ for decay mode 3 . The whole observation was made in a season when the soil moisture varied widely from 0.151 to $0.370 \mathrm{~m}^{3} / \mathrm{m}^{3}$. The $\mathrm{CO}_{2}$ releasing experiment was in a fairly wet season, and the soil moisture varied from 0.202 to $0.347 \mathrm{~m}^{3} / \mathrm{m}^{3}$. The observed results above may be closely related with these wet conditions. If the moisture is too low, dissolution of $\mathrm{CO}_{2}$ in soil might be very low, and the increase in soil $\mathrm{EC}$ as a result of $\mathrm{CO}_{2}$ leakage might be very limited. If the soil is saturated during a rainstorm, the soil pores are filled with water, resulting in quick depletion of the residual $\mathrm{CO}_{2}$. Between the low and high moisture limits, the impact of $\mathrm{CO}_{2}$ leakage on soil bulk EC is optimal.

Soil $\mathrm{CO}_{2}$ concentration after the termination of $\mathrm{CO}_{2}$ release was observed to increase with increasing soil moisture, indicating that soil $\mathrm{CO}_{2}$ concentration was not washed down due to dissolution $\mathrm{CO}_{2}$ into infiltrating water. The soil moisture in the very topsoil at the beginning of a rainfall might create an effective barrier to free diffusive exchange between the soil and the atmosphere. Clearly it also depends on the amount of rainfall and if it infiltrates deep enough in the vadose zone.

From Fig. 5 we can see that when the soil $\mathrm{CO}_{2}$ is high for the periods during $\mathrm{CO}_{2}$ release and the first 2 days post release, the bulk soil EC versus soil moisture has a quite different trend than when the soil $\mathrm{CO}_{2}$ concentration is low for the post release after 2 days of termination of the $\mathrm{CO}_{2}$ release. At the same soil moisture level, the case with higher soil $\mathrm{CO}_{2}$ due to $\mathrm{CO}_{2}$ leakage has a higher soil bulk EC value, especially when soil moisture is high $(>21 \%)$. Kalinski and Kelly (1993) found that at any given water content, the soil EC increases when the soil water conductivity increases. Comparison of the results shown in Fig. 5 with those of Kalinski and Kelly (1993) suggested that the soil water during $\mathrm{CO}_{2}$ leakage has higher conductivity because of dissolution of $\mathrm{CO}_{2}$. Therefore, the soil EC method should be useful in aiding the detection of $\mathrm{CO}_{2}$ leakage at the $\mathrm{CO}_{2}$ geological sequestration sites. However, since the soil moisture is the solvent for $\mathrm{CO}_{2}$ to dissolve and to enhance the soil conductivity, a certain degree of soil moisture may have to be reached in order for it to be applicable.

The cost of large-scale monitoring of geologic storage of $\mathrm{CO}_{2}$ is a paramount concern. The different relationships between EC and soil moisture could be used to provide an early warning of possible $\mathrm{CO}_{2}$ leakage. Since the measurement of EC and soil moisture is automated and inexpensive, a large-scale network of EC-soil moisture monitoring systems can generate important and cost-effective results. Development of such a surface-monitoring network can be used instead of, or in addition to, monitoring wells.
We conclude that: (1) At the present soil moisture conditions (varying between 0.151 to $0.370 \mathrm{~m}^{3} / \mathrm{m}^{3}$ ), the relationship between the bulk soil EC and soil moisture observes completely different laws when there is $\mathrm{CO}_{2}$ leakage as compared to when there is no $\mathrm{CO}_{2}$ leakage. $\mathrm{CO}_{2}$ leakage causes an increase in the soil bulk EC when the soil moisture is above a certain level $(>21 \%)$ and the increment in soil EC due to $\mathrm{CO}_{2}$ leakage increases with increasing soil moisture. As a first order of approximation, the bulk soil EC is linearly correlated with soil moisture, but the slope is more than doubled (increases from 2.067 to $4.982 \mathrm{dS} / \mathrm{m}$ ) when the soil $\mathrm{CO}_{2}$ concentration is above the background $\mathrm{CO}_{2}$ concentration due to $\mathrm{CO}_{2}$ leakage. (2) Multivariate regression analyses of bulk soil EC with soil moisture and soil temperature for during-release and post-release phases show that the coefficient for soil moisture was increased from $2.111 \mathrm{dS}$ for the non-leaking phase to $4.589 \mathrm{dS}$ for the $\mathrm{CO}_{2}$ leaking phase; that for temperature was increased from 0.003 to $0.008 \mathrm{dS} /{ }^{\circ} \mathrm{C}$. This may indicate that high soil $\mathrm{CO}_{2}$ concentration due to $\mathrm{CO}_{2}$ leakage enhances the dependence of soil bulk EC on both soil moisture and soil temperature, though the dependence of bulk soil EC on soil temperature is generally weak. (3) After the termination of $\mathrm{CO}_{2}$ release, the relationship between soil bulk EC and soil $\mathrm{CO}_{2}$ concentration observes three distinct decay modes that are mainly controlled by rainfall events and high soil $\mathrm{CO}_{2}$ concentration. (4) Within each decay mode, increasing soil $\mathrm{CO}_{2}$ concentration results in higher bulk soil EC. Comparing the first 2 decay modes, it is found that the dependence of bulk soil $\mathrm{EC}$ on soil $\mathrm{CO}_{2}$ concentration is weaker for the first decay mode than for the second decay mode. The number of decay modes may depend on the rainfall events when the soil $\mathrm{CO}_{2}$ concentration is sufficiently higher than the background $\mathrm{CO}_{2}$ concentration level. However, the decay modes presented here may be very useful in predicting responses of soil to $\mathrm{CO}_{2}$ leakage, and thus have important ramifications in surface detection of $\mathrm{CO}_{2}$ leakage from carbon sequestration fields.

\section{Acknowledgments}

This work was funded by the US Department of Energy EPSCoR program under grant number DE-FG02-08ER46527 and the Zero Emissions Research and Technology (ZERT) program (DOE award no. DE-FC26-04NT42262).

\section{References}

Aachib, M., Mbonimpa, M., Aubertin, M., 2004. Measurement and prediction of the oxygen diffusion coefficient in unsaturated media, with applications to soil covers. Water, Air, and Soil Pollution 156, 163-193.

Adviento-Borbe, M.A.A., Doran, J.W., Drijber, R.A., Dobermann, A., 2006. Soil electrical conductivity and water content affect nitrous oxide and carbon dioxide emissions in intensively managed soils. Journal of Environmental Quality 35, 1999-2010.

Alexander, D., Bryant, S.L., 2009. Evaluating storage and leakage scenarios for carbon diode sequestration in Trinidad and Tobago. Energy Procedia 1, 2761-2768.

Annunziatellis, A., Beaubien, S.E., Bigi, S., Ciotoli, G., Coltella, M., Lombardi, S., 2008 Gas migration along fault systems in the Latera natural analogue (central Italy): implications for $\mathrm{CO}_{2}$ geological storage. International Journal of Greenhouse Gas Control 2 (3), 353-372.

Arts, R.J., Baradello, L., Girard, J.F., Kirby, G., Lombardi, S., Williamson, P., Zaja, A., 2009. Results of geophysical monitoring over a "leaking" natural analogue site in Italy. Energy Procedia 1, 2269-2276.

Avrahami, S., Conrad, R., Braker, G., 2002. Effect of soil ammonium concentration on $\mathrm{N}_{2} \mathrm{O}$ release and on the community structure of ammonia oxidizers and denitrifiers. Applied and Environmental Microbiology 68, 5685-5692.

Bachu, S., Adams, J.J., 2003. Sequestration of $\mathrm{CO}_{2}$ in geological media in response to climate change: capacity of deep saline aquifers to sequester $\mathrm{CO}_{2}$ in solution. Energy Conversion and Management 44, 3151-3175.

Banton, O., Seguin, M.K., Cimon, M.A., 1997. Mapping field scale physical properties of soil with electrical resistivity. Soil Science Society of America Journal 61, 1010-1017.

Beaubien, S.E., Ciotoli, G., Coombs, P., Dictor, M.C., Krüger, M., Lombardi, S., Pearce J.M., West, J.M., 2008. The impact of a naturally occurring $\mathrm{CO}_{2}$ gas vent on the shallow ecosystem and soil chemistry of a Mediterranean pasture (Latera, Italy). International Journal of Greenhouse Gas Control 2 (3), 373-387.

Birkholzer, J., Apps, J.A., Zheng, L., Zhang, Z., Xu, T., Tsang, C.-F., 2008. Research project on $\mathrm{CO}_{2}$ geological storage and groundwater resources: water quality 
effects caused by $\mathrm{CO}_{2}$ intrusion into shallow groundwater. Lawrence Berkeley National Laboratory Technical Report. LBNL-1251E, 450 p.

Bouc, O., Audigane, P., Bellenfant, G., Fabriol, H., Gastine, M., Rohmer, J., Seyedi, D., 2009. Determining safety criteria for $\mathrm{CO}_{2}$ geological storage. Energy Procedia 1 , 2439-2446.

Carroll, J., Slupsky, J.D., Mather, A.E., 1991. The solubility of carbon dioxide in water at low pressure. Journal of Physical and Chemical Reference Data 20,1201-1209.

Carroll, S., Hao, Y., Aines, R., 2009. Geochemical detection of carbon dioxide in dilute aquifers. Geochemical Transaction 10 (4), doi:10.1186/1467-4866-10-14.

Celia, M.A., Nordbotten, J.M., Bachu, S., Dobossy, M., Court, B., 2009. Risk of leakage versus depth of injection in geological storage. Energy Procedia 1, 2573-2580.

Chang, K.W., Bryant, S.L., 2009. The effect of faults on dynamics of $\mathrm{CO}_{2}$ plumes. Energy Procedia 1, 1839-1846.

Cunningham, A.B., Gerlach, R., Spangler, L., Mitchell, A.C., 2009. Microbially enhanced geologic containment of sequestered supercritical $\mathrm{CO}_{2}$. Energy Procedia 1, 3245-3252.

Eigenberg, R.A., Woodbury, B.L., Nienaber, J.A., Spiehs, M.J., Parker, D.B., Varel, V.H., 2010. Soil conductivity and multiple linear regression for precision monitoring of beef feedlot manure and runoff. Journal of Environmental and Engineering Geophysics 15 (3), 175-184.

Enick, R.M., Klara, S.M., 1990. $\mathrm{CO}_{2}$ Solubility in water and brine under reservoir conditions. Chemical Engineering Communications 90 (1), 23-33.

Frankenberger Jr., W.T., Bingham, F.T., 1982. Influence of salinity on soil enzyme activities. Soil Science Society of America Journal 46, 1173-1177.

Fukue, M., Minatoa, T., Horibe, H., Taya, N., 1999. The microstructure of clay given by resistivity measurements. Engineering Geology 54, 43-53.

Gasda, S.E., Bachu, S., Celia, M.A., 2004. Spatial characterization of the location of potentially leaky wells penetrating a deep saline aquifer in a mature sedimentary basin. Environmental Geology 46, 707-720.

Grimstad, A.-A., Georgescu, S., Lindeberg, E., Vuillaume, J.-F., 2009. Modelling and simulation of mechanisms for leakage of $\mathrm{CO}_{2}$ from geological storage. Energy Procedia 1, 2511-2518.

Haywood, H.M., Eyre, J.M., Scholes, H., 2001. Carbon dioxide sequestration as stable carbonate minerals - environmental barriers. Environmental Geology 41, 11-16.

Hepple, R.P., Benson, S.M., 2005. Geologic storage of carbon dioxide as a climate change mitigation strategy: performance requirements and the implications of surface seepage. Environmental Geology 47, 576-585.

Holloway, S., 2001. Storage of fossil fuels-derived carbon dioxide beneath the surface of the earth. Annual Review of Energy and the Environment 26, 145-166.

IPCC (Intergovernmental Panel on Climate Change), 2005. Special report on carbon dioxide capture and storage [B. Metz, O. Davidson, H. de Coninck, M. Loos, and L. Meyer (Eds.)]. Cambridge University Press, Cambridge, UK, and New York, NY, USA.

Irshad, M., Honna, T., Yamamoto, S., Eneji, A.E., Yamasaki, N., 2005. Nitrogen mineralization under saline conditions. Communications in Soil Science and Plant Analysis 36, 1681-1689.

Jackson, P.D., Taylor Smith, D., Stanfords, P.N., 1978. Resistivity-porosity-particle shape relationships for marine sand. Geophysics 43 (3), 1250-1268.

Kalinski, R.J., Kelly, W.E., 1993. Estimating water content of soils from electrical resistivity. Geotechnical Testing Journal 16, 323-329.

Kharaka, Y.K., Cole, D.R., Hovorka, S.D., Gunter, W.D., Knauss, K.G., Freifeld, B., 2006 Gas-water-rock interactions in Frio Formation following $\mathrm{CO}_{2}$ injection: implications for the storage of greenhouse gases in sedimentary basins. Geology 34 577-580.

Kharaka, Y.K., Thordsen, J.J., Kakouros, E., Ambats, G., Herkelrath, W.N., Beers, S.R Birkholzer, J.T., Apps, J.A., Spycher, N.F., Zheng, L., Trautz, R.C., Rauch, H.W., Gullickson, K.S., 2010. Changes in the chemistry of shallow groundwater related to the 2008 injection of $\mathrm{CO}_{2}$ at the ZERT field site, Bozeman, Montana. Environmental Earth Sciences 60, 273-284.

Kiessling, D. Schmidt-Hattenberger, C., Schuett, $H_{\text {, Schilling }}$., Krueger, $K$, Schoebel, B., Danckward, E., Kummerow, J., the CO2SINK Group, 2010. Geoelectrical methods for monitoring geological $\mathrm{CO}_{2}$ storage: first results from cross-hole and surface-downhole measurements from the CO2SINK test site at Ketzin (Germany). International Journal of Greenhouse Gas Control 4, 816-826.

Killham, K., Firestone, M.K., 1984. Salt stress control of intracellular solutes in Streptomycetes indigenous to saline soils. Applied and Environmental Microbiology 47, 301-306.

Krüger, M., West, J., Frerichs, J., Oppermann, B., Dictor, M.-C., Joulian, C., Jones, D., Coombs, P., Green, K., Pearce, J., May, F., Möller, I., 2009. Ecosystem effects of elevated $\mathrm{CO}_{2}$ concentrations on microbial populations at a terrestrial $\mathrm{CO}_{2}$ vent at Laacher See, Germany. Energy Procedia 1, 1933-1939.

Lakkaraju, V.R., Zhou, X., Apple, M.E., Cunningham, A., Dobeck, L.M., Gullickson, K., Spangler, L.H., 2010. Studying the vegetation response to simulated leakage of sequestered $\mathrm{CO}_{2}$ using spectral vegetation indices. Ecological Informatics 5, 379-389.

Laura, R.D., 1974. Effects of neutral salts on carbon and nitrogen mineralization of organic matter in soil. Plant Soil 41, 113-127.

Levitt, J., 1980. Responses of Plants to Environmental Stresses, vol. 2., 2nd ed. Academic Press, New York.

Lewicki, J.L., Hilley, G.E., Dobeck, L., Spangler, L., 2010. Dynamics of $\mathrm{CO}_{2}$ fluxes and concentrations during a shallow subsurface $\mathrm{CO}_{2}$ release. Environmental Earth Sciences 60, 285-297.

Lindsay, W.L., 1979. Chemical Equilibria in Soils. Wiley, New York.

Liu, G.-M., Yang, J.-S., Yao, R.-J., 2006. Electrical conductivity in soil extracts: chemical factors and their intensity. Pedosphere $16(1), 100-107$.
Lloyd, J., Taylor, J.A., 1994. On the temperature dependence of soil respiration. Functional Ecology 8, 315-323.

Luo, Y., Zhou, X., 2006. Soil Respiration and the Environment. Elsevier, Inc., Burlington, Massachusetts.

Macek, I., Pfanz, H., Francetic, V., Batic, F., Vodnik, D., 2005. Root respiration response to high $\mathrm{CO}_{2}$ concentrations in plants from natural $\mathrm{CO}_{2}$ springs. Environmenta and Experimental Botany 54, 90-99.

McCafferty, A.E., Van Gosen, B.S., Krevor, S.C., Graves, C.R., 2009. Geophysical delineation of Mg-rich ultramafic rocks for mineral carbon sequestration. U.S. Geological Survey Open-File Report, 2009-1127, 24 p.

McMahon, P.B., Vroblesky, D.A., Bradley, P.M., Chapelle, F.H., Guller, C.D., 1995. Evidence of enhanced mineral dissolution in organic acid-rich shallow ground water. Ground Water 33, 207-216.

McCarter, W.J., 1984. The electrical resistivity characteristics of compacted clays. Géotechnique 34, 263-267.

Michot, D., Benderitter, Y., Dorigny, A., Nicoullaud, B., King, D., Tabbagh, A., 2003. Spatial and temporal monitoring of soil water content with an irrigated corn crop cover using electrical resistivity tomography. Water Resources Research 39 (5), 1138, doi:10.1029/2002WR001581.

Oldenburg, C.M., Unger, A.J.A., 2003. On leakage and seepage from geologic carbon sequestration sites: unsaturated zone attenuation. Vadose Zone Journal 2 , 287-296.

Oldenburg, C.M., Lewicki, J.L., Pan, L., Dobeck, L., Spangler, L., 2010. Origin of the pachy emission pattern at the ZERT $\mathrm{CO}_{2}$ release test. Environmental Earth Sciences 60, 241-250.

Pearson, E.S., Hartley, H.O. (Eds.), 1966. Biometrika Tables for Statisticians, vol. 1, 3rd ed. Cambridge University Press, New York.

Pettinelli, E., Beaubien, S.E., Lombardi, S., Annan, A.P., 2008. GPR, TDR, and geochemistry measurements above an active gas vent to study near-surface gas-migration pathways. Geophysics 73 (1), A11-A15.

Pfanz, H., Vodnik, D., Wittmann, C., Aschan, G., Batic, F., Turk, B., Macek, I., 2007. Photosynthetic performance $\left(\mathrm{CO}_{2}\right.$-compensation point, carboxylation efficiency, and net photosynthesis) of timothy grass (Phleum pratense L.) is affected by elevated carbon dioxide in post-volcanic mofette areas. Environmental and Experimental Botany 61, 41-48.

Pruess, K., 2005. Numerical studies of fluid leakage from a geologic disposal reservoir for $\mathrm{CO}_{2}$ show self-limiting feedback between fluid flow and heat transfer. Geophysical Research Letters 32, L14404, doi:10.1029/2005GL023250.

Rasmuson, A., Gimmi, T., FluÈhler, H., 1990. Modeling reactive gas uptake, transport and transformation in aggregated soils. Soil Science Society of America Journal $54,1206-1213$.

Raven, J.A., Falkowski, P.G., 1999. Oceanic sinks for atmospheric $\mathrm{CO}_{2}$. Plant, Cell and Environment 22, 741-755.

Rhoades, J.D., 1993. Electrical conductivity methods for measuring and mapping soil salinity. Advances in Agronomy 49, 201-251.

Rhoades, J.D., Chanduvi, F., Lesch, S., 1999. Soil salinity assessment: methods and interpretation of electrical conductivity measurements. FAO Irrigation and Drainage Paper No. 57. Food and Agriculture Organization of the United Nations, Rome, 166 p.

Samouëlian, A., Cousin, I., Tabbagh, A., Bruand, A., Richard, G., 2005. Electrical resistivity survey in soil science: a review. Soil and Tillage Research 83, 173-193.

Smith, J.L., Doran, J.W., 1996. Measurement and use of pH and electrical conductivity. In: Doran, J.W., Jones, A.J. (Eds.), Methods for Assessing Soil Quality. SSSA Spec. Pub. 49. SSSA, Madison, WI, pp. 169-185.

Spangler, L.H., Dobeck, L.M., Repasky, K.S., Nehrir, A.R., Humphries, S.D., Barr, J.L. Keith, C.J., Shaw, J.A., Rouse, J.H., Cunningham, A.B., Benson, S.M., Oldenburg, C.M., Lewicki, J.L., Wells, A.W., Diehl, J.R., Strazisar, B.R., Fessenden, J.E., Rahn, T.A., Amonette, J.E., Barr, J.L., Pickles, W.L., Jacobson, J.D., Silver, E.A., Male, E.J., Rauch, H.W., Gullickson, K.S., Trautz, R., Kharaka, Y., Birkholzer, J., Wielopolski, L., 2010. A shallow subsurface controlled release facility in Bozeman, Montana, USA, for testing near surface $\mathrm{CO}_{2}$ detection techniques and transport models. Environmental Earth Sciences 60, 227-239.

Stephens, J.C. Hering, J.G., 2002. Comparative characterization of volcanic ash soils exposed to decade-long elevated carbon dioxide concentrations at Mammoth Mountain, California. Chemical Geology 186, 301-313.

Stephens, J.C., Hering, J.G., 2004. Factors affecting the dissolution kinetics of volcanic ash soils: dependencies on $\mathrm{pH}, \mathrm{CO}_{2}$, and oxalate. Applied Geochemistry 19 (8), 1217-1232.

Wang, S., Jaffe, P.R., 2004. Dissolution of a mineral phase in potable aquifers due to $\mathrm{CO}_{2}$ releases from deep formations; effect of dissolution kinetics. Energy Conversion and Management 45 (18-19), 2833-2848.

West, J.M., Pearce, J.M., Coombs, P., Ford, J.R., Scheib, C., Colls, J.J., Smith, K.L., Steven, M.D., 2009. The impact of controlled injection of $\mathrm{CO}_{2}$ on the soil ecosystem and chemistry of an English lowland pasture. Energy Procedia 1, 1863-1870.

Wiebe, R., Gaddy, V.L., 1940. The solubility of carbon dioxide in water at various temperatures from 12 to $40^{\circ}$ and at pressures to 500 atmospheres. Critical phenomena. Journal of the American Chemical Society 62 (4), 815-817.

Williams, F., 1992. Reasoning with Statistics: How to Read Quantitative Research. Harcourt Brace Jovanovich, Fort Worth, TX.

Xu, T., Apps, J.A., Pruess, K., 2003. Reactive geochemical transport simulation to study mineral trapping for $\mathrm{CO}_{2}$ disposal in deep arenaceous formations. Journal of Geophysical Research 108 (B2), 2071, doi:10.1029/2002JB001979.

Zheng, L., Apps, J.A., Zhang, Y., Xu, T., Birkholzer, J.T., 2009. Reactive transport simulations to study groundwater quality changes in response to $\mathrm{CO}_{2}$ leakage from deep geological storage. Energy Procedia 1, 1887-1894. 